Témoigner Témoigner. Entre histoire et mémoire

Getuigen Revue pluridisciplinaire de la Fondation Auschwitz

$121 \mid 2015$

Violences radicales en scène

\title{
Kunst moet schuren
}

Interview met Chokri Ben Chikha

Kunst moet schuren. Interview met Chokri Ben Chikha

\section{Evelien Jonckheere et Chokri Ben Chikha}

\section{(2) OpenEdition}

Journals

Édition électronique

URL : https://journals.openedition.org/temoigner/3460

DOI : $10.4000 /$ temoigner.3460

ISSN : 2506-6390

Éditeur :

Éditions du Centre d'études et de documentation Mémoire d'Auschwitz, Éditions Kimé

Édition imprimée

Date de publication : 1 octobre 2015

Pagination : 133-139

ISSN : 2031-4183

Référence électronique

Evelien Jonckheere en Chokri Ben Chikha, «Kunst moet schuren», Témoigner. Entre histoire et mémoire [Online], 121 | 2015, Online op 01 octobre 2016, geraadpleegd op 04 février 2022. URL: http:// journals.openedition.org/temoigner/3460 ; DOI: https://doi.org/10.4000/temoigner.3460 


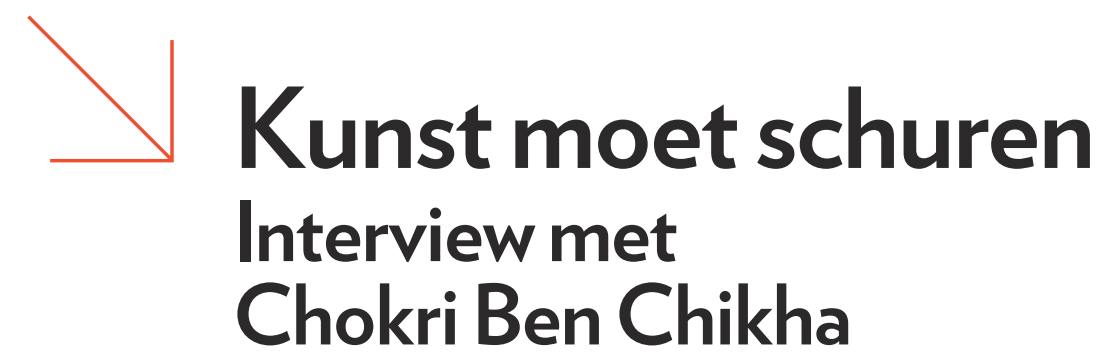

$\rightarrow$ Evelien Jonckheere, UGent

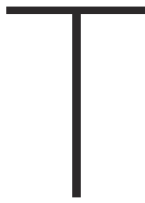

ussen 2007 en 2013 bereidde Chokri Ben Chikha aan het KASK en de UGent een doctoraatsproject voor dat hem uiteindelijk de titel van 'doctor in de kunsten' zou opleveren. Via diverse theatrale experimenten onderzocht hij het gebruik van stereotypen in het theater. Daarbij ging hij na hoe je, via systemen van constructie en deconstructie, stereotypen als theaterteken kunt inzetten om een kritische reflectie uit te lokken bij de toeschouwer.

De experimenten binnen dit project monden uit in de oprichting van het gezelschap Action Zoo Humain in 2009. Een jaar later staat de Heldentrilogie op punt. Eén stuk daarvan speelt zich af in Senegal (L'Afrique c'est chic), een ander in

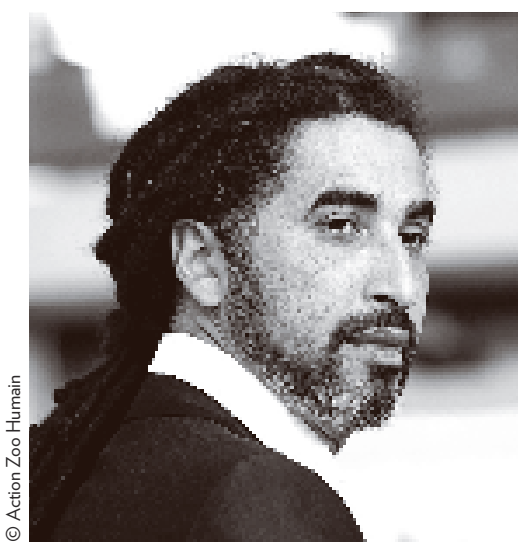
de straten van Vlaanderen (De ceremonie: heldendood voor de beschaving) en nog een in de theaterzaal (Definale: een stand-uptragedie). Uiteindelijk vormt De Waarheidscommissie in 2013 het slotstuk van de theatrale experimenten binnen Ben Chikha's doctoraatsonderzoek. De toneelmaker was hiermee echter niet aan zijn proefstuk toe. Onder de vleugels van het gezelschap Union Suspecte creëerde hij eerder een familiedrieluik bestaande uit De leeuw van Vlaanderen (2003), Onze Lieve Vrouw van Vlaanderen (2005) en Broeders van Liefde (2007). Reeds in die eerste trilogie speelt Ben Chikha met stereotypen, en merken we zijn verlangen om op die manier het debat rond identiteit en migratie aan te wakkeren.

In een gesprek met Ben Chikha gaan we op zoek naar ervaringen en ontmoetingen uit het verleden die bepalend waren voor de strategieën die hij toepast in zijn oeuvre en dat van Action Zoo Humain.

In je doctoraat beschrijf je dat je het gegeven van de zoo humain als een prisma beschouwt om naar ander werk en naar je eigen voorstellingen te kijken. Je beschouwt het als een 'historisch format van stereotiepe culturele representatie'. Hoe kwam je terecht bij het historische fenomeen van de zoo humain?

Chokri Ben Chikha: Na twee jaar onderzoek had ik het gevoel dat ik in een cirkeltje aan het draaien was. Ik had een zekere afstand nodig om het gegeven van stereotypen op theater te onderzoeken. Tijdens de lezing Pourquoi travailler sur les images et stéréotypes d'hier? Les enjeux d'une décolonisation du regard (Brussel, 24 juni 


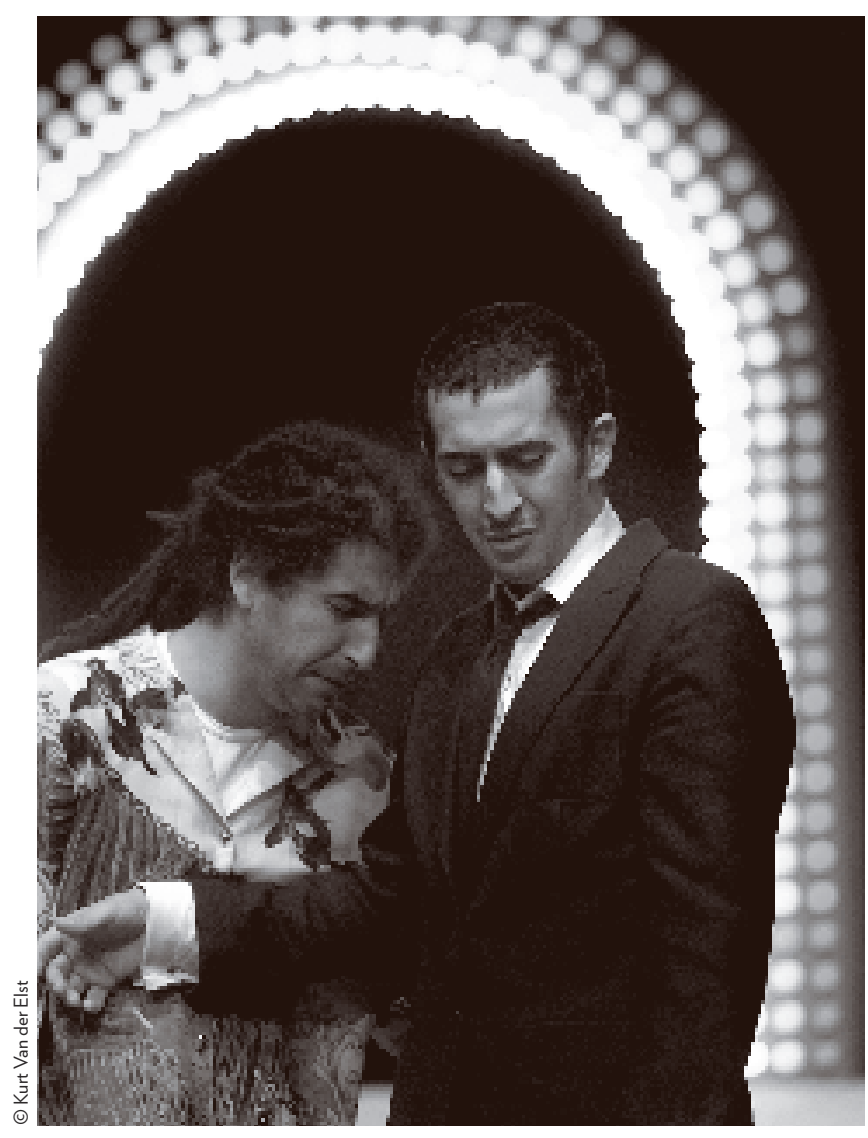

_ Onze Lieve Vrouw van Vlaanderen, Union Suspecte, 2005.
2008) van de Franse historicus Pascale Blanchard werd ik voor het eerst geconfronteerd met het gegeven van de zoo humain. Het was een lezing zonder enige vorm van beeldmateriaal, maar die liet niettemin een grote indruk na. Al gauw zag ik in dat ik het gegeven van de zoo humain als paraplu kon gebruiken. Net als bij de De leeuw van Vlaanderen, waar ik aan de hand van een historische roman met voldoende afstand mijn verhaal kon doen, kon ik met de zoo humain als onderzoeksinstrument opnieuw vanuit een historisch gegeven met enige afstand de stereotypen in theater blootleggen.

Kunstenaars als Brett Bailey maken eveneens gebruik van het gegeven van de zoo humain om theatervoorstellingen te maken. Je schreef zelfs een brief aan Bailey waarin je aangeeft dat je niet akkoord gaat met zijn werkwijze in de voorstelling Exhibit B (2012). Nochtans werd Bailey in de Vlaamse pers nauwelijks bekritiseerd. Hoe verklaar je dit?

C.B.C.: Dat Vlaamse cultuurjournalisten niet begrijpen dat Bailey een commotie teweegbrengt, geeft aan dat er hier in Vlaanderen een tekort is aan kennis over de continuïteit en het voortdurende effect van het koloniale denken op ons huidige postkoloniale denken. Toen ik die voorstelling zag, wist ik dat er iets niet klopte. Door het feit dat hij de Afrikanen op dezelfde manier tentoonstelt als 150 jaar geleden, maar daarbij geen context aanreikt of zichzelf niet in vraag stelt als theatermaker die dergelijke zaken ensceneert, stereotypeert hij net als de historische zoo humain de 'exoot'. Niet door de Ander als wild of achterlijk voor te stellen, maar als passief slachtoffer. Had hij bijvoorbeeld zichzelf als blanke Afrikaan actief in de voorstelling betrokken, was de voorstelling heel wat interessanter geweest. Men begrijpt niet hoe choquerend dergelijke voorstellingen voor bepaalde groepen zijn, ook vandaag nog. Het stereotiepe beeld van de zwarte die monddood wordt gemaakt, wordt hier gewoon herhaald, want er komt geen andere stem in de performance voor, er is geen gelaagdheid. Nochtans zie je internationaal wel veel kritiek op Bailey. In Engeland, Frankrijk en Duitsland is de discussie veel heviger, terwijl critici en programmatoren in Vlaanderen niet verder gaan dan: 'Waw, wat een toffe aanklacht tegen racisme.' Dat ze in Engeland de voorstelling afgelasten vind ik dan weer een brug te ver. Maar een debat koppelen aan de voorstelling, dat vind ik noodzakelijk. 
Hoe sta je dan bijvoorbeeld tegenover de documentaire Enjoy Poverty (2008) van Renzo Martens? De maker legt daar op cynische wijze de scheefgetrokken machtsverhoudingen bloot tussen het Westen en Congo. De tegenstelling 'zij die kijken' vs. 'zij die bekeken worden' brengt een zekere gelaagdheid in de documentaire.

C.B.C.: In vergelijking met Bailey was Renzo Martens veel inspirerender. Martens neemt zelf actief deel aan het gebeuren. Waar ik het dan wel weer moeilijk mee heb bij Enjoy Poverty is het feit dat de maker geen enkele kritische Afrikaan in beeld brengt. Denkje nu echt dat er geen enkele Congolees is die kritische analyses kan maken over ontwikkelingshulp? Zo bevestig je natuurlijk weer de stereotypen. Zowel Exibit B als Enjoy Poverty komen voor vele zwarten als blank paternalisme over, terwijl beide artiesten dit menen aan te klagen. De werken op zich zijn zeer interessant, maar de analyse en de kritiek errond vind ik steevast nog veel interessanter.

In je doctoraat geef je aan dat de voorstelling Missie (2007), een monoloog geschreven door David Van Reybrouck en gebaseerd op tientallen getuigenissen van missionarissen, jou als 'documentair theater' wist te inspireren voor De Waarheidscommissie. Toch werd ook deze voorstelling volgens jou te weinig kritisch onthaald.

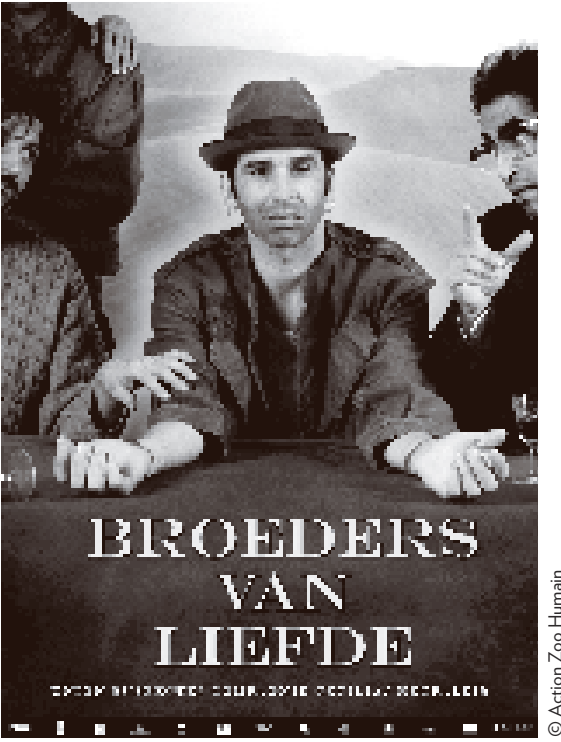

C.B.C.: Bij Missie zag ik de kracht van de subjectieve en de feitelijke waarheid, en van de mix daarvan. Het verhaal wordt voorgesteld als de waarheid van een zogenaamde autoriteit, iemand die het heeft meegemaakt, in dit geval diverse missionarissen. De mensen waren ervan overtuigd dat het stuk 'waar' was, omdat het was gebaseerd op een verzameling van 'autoritaire' getuigenissen. Terwijl het overgrote deel natuurlijk subjectieve (koloniale) waarheid is. Dus ook deze voorstelling ontbrak het aan meerstemmigheid. Met uitzondering van Bambi Ceuppens stelde niemand in de Vlaamse pers zich vragen bij de eenzijdigheid van het verhaal, of de manier waarop zwarten werden voorgesteld in Missie. Ik wist niet dat mensen zo goedgelovig waren. Ik zag dus de kracht in van de zogenaamde 'waarheid', en de kracht van autoriteit. Vandaar dat ik voor De Waarheidscommissie inzette op waargebeurde historische feiten. Ik deed dat met behulp van jouw onderzoekswerk ${ }^{1}$ en door beroep te doen op een andere autoriteit, namelijk voormalig gouverneur van Oost-Vlaanderen en professor geschiedenis Herman Balthazar. Door waargebeurde feiten en autoriteiten vervolgens te laten clashen met subjectieve waarheden in getuigenissen van Senegalese, Franse en Belgische artiesten in woord, dans en muziek, kreeg je een gelaagde complexiteit.

Zo wordt de toeschouwer in De Waarheidscommissie geconfronteerd met verschillende waarheden. Je ziet bijvoorbeeld hoe Mourade, zelf een soort van slachtoffer van de hedendaagse maatschappij, op een bepaald moment tekeergaat tegen de Senegalezen en ook hen slachtoffer maakt. Ik vind dat kritiek op mensen met een migratieverleden ook moet kunnen. Beweren dat het allemaal slachtoffers zijn, is

(1) Evelien Jonckheere onderzocht de historische context van de zoo humain in Gent in 1913 aan de hand van documentatie uit het vreemdelingenregister in het Rijksarchief te Brussel. De resultaten van dit historische onderzoek verschenen in het boekhoofdstuk 'Ach, Waarom zou ik het u ook verzwijgen? ... Ontbering achter de schermen van de "zoos humains" in Wouter Van Acker \& Christophe Verbruggen (red.), Gent 1913: op het breukvlak van de moderniteit (Gent: Snoeck, 2013, 96-111). Als 'expert' trad ze vervolgens aan als getuige in De Waarheidscommissie om het historische kader tijdens de voorstelling toe te lichten. 
een vrijgeleide. Die kritiek op de eigen afkomst was ook een belangrijk en uitdagend aspect in de De leeuw van Vlaanderen, waar we afgeven op onze autoritaire vader. De werkelijkheid is complexer dan één waarheid. In de werkelijkheid grijpen immers de feitelijke, de subjectieve en de intersubjectieve waarheid in elkaar. Door hiermee een performatieve waarheid te creëren, krijg je, als het meezit, iets helends.

Die zin voor complexiteit, bijvoorbeeld via kritiek op de eigen afkomst, deel ik met de schrijver Arnon Grunberg. Ook hij vertrekt vanuit autobiografische elementen maar durft af te rekenen met zijn Joodse afkomst. Ook hij heeft geen behoefte aan de verheerlijking van de underdog, want de underdog kan evenzeer dader zijn. Ook bij hem zie je het gebruik van stereotypen die worden uitvergroot tot ze absurd worden. Zo vervaagt de grens tussen fictie en realiteit. Net als ik zoekt hij naar de clash van diverse waarheden. Daarachter gaat een enorm engagement schuil. Dat absurdisme, en dat opzoeken van kritiek, vind ik zeer interessant. Dat is misschien waarom ik volgens sommigen een halve charlatan ben, en volgens anderen vernieuwend.

Waarom is Vlaanderen niet altijd 'mee' met voorstellingen als Exhibit B en Missie? Komt dat door het feit dat het Vlaamse theaterlandschap en haar publiek overwegend blank is? Wat kan het Vlaamse theater doen om daar verandering in te brengen?

C.B.C.: Het blanke gegeven van het Vlaamse theater is het gevolg van het feit dat men in de theaterwereld goed zorg draagt voor elkaar. Dat is ook normaal, want iedereen zoekt telkens naar het eigen referentiekader. Maar daardoor durf ik bijna te stellen dat theater geen progressief circuit is, eerder eentje dat zichzelf in stand houdt. Wat volgens mij zou helpen is de invoering van quota om meer vrouwen en mensen van andere origine aan de bak te brengen. Zeker in de hogere regionen van het theater is er behoefte aan diversiteit. Want enkel als je de leiding neemt, kan je veranderingen doorvoeren. En gewoon wat meer kleur op het podium brengen, betekent nog niet dat je met interculturaliteit bezig bent.

Maar begrijp me niet verkeerd. Ondanks deze kritiek op het Vlaamse theater hou ik er erg veel van en vind ik het belangrijk dat theater overal zichtbaar is. We hebben alternatieven nodig voor internet en YouTube. De belastingbetaler heeft er trouwens recht op. Maar vele theaterhuizen en -gezelschappen zijn hun maatschappelijke betekenis aan het verliezen. Wil theater in de toekomst nog relevant zijn, dan moet zij op een artistieke manier kunnen bijdragen om het 'spel' binnen de gepolariseerde en superdiverse (groot)steden speelbaar te maken. Wat gaat het theater doen als binnenkort vijftig procent van de stedelingen een andere origine hebben? Of als verschillende bevolkingsgroepen elkaar naar de keel grijpen uit angst, wraak of soms stomweg door een misverstand? Viool spelen op de Titanic?

\section{Hoe ben jij eigenlijk in het theater gerold? Werd dit van thuis uit gestimuleerd?}

C.B.C.: Nee. Ik rolde in het theater vanuit mijn liefde voor Afrikaanse dans. Ik kwam hiermee in contact toen ik in het kader van mijn geschiedenisopleiding op Erasmusuitwisseling ging naar Amsterdam. Al snel wilde ik lessen volgen bij dansers en choreografen die opgeleid waren aan de Mudra-Afrique school, die in 1977 door 
Maurice Béjart werd opgericht in Dakar. Om mijn reis te bekostigen, gaf ik zelf lessen Afrikaanse dans aan studenten en moeders. In Senegal kreeg ik les van zogenaamde 'dansmeesters' die toen nog werkten in een internationale context. Hun dans was doorspekt met veel West-Afrikaanse tradities: veel mime in een expliciet en interdisciplinair spektakel dat je nog het best met opera kan vergelijken. Via Béjart kwamen daar elementen uit de klassieke dans bij. Hij wist het dansspektakel bovendien te commercialiseren. De school reisde de wereld rond, wat vandaag jammer genoeg onmogelijk geworden is vanwege het feit dat Afrikaanse artiesten heel snel de benen nemen zodra ze in Europa of de Verenigde Staten aankomen. ${ }^{2}$

Terug in Europa ging ik verder op zoek naar een innovatieve manier om met Afrikaanse dans om te gaan. Ik won de tweede prijs in Parijs op het 'Concours International d'inspiration africaine'. De jury werd voorgezeten door Germaine Acogny, voormalig directrice van Mudra-Afrique. Na een mislukte auditie bij Hans Van Den Broeck van Ballets C de la B maakte ik uiteindelijk in 1999 mijn overstap naar de Belgische scène als percussionist en danser bij de voorstelling K'Dar van het gezelschap Hush hush hush onder leiding van Abdelaziz Sarrokh. Bij deze voorstelling stond de mengeling van genres en stijlen centraal. De mix van breakdance met opzwepende Afrikaanse dans bracht een nieuwe kijk op hedendaagse dans en bereikte een breed publiek. Niettemin was de voorstelling naar mijn mening inhoudelijk zwak. De choreograaf zei toen: kun je het beter, doe het dan zelf! Zo ontstond uiteindelijk Union Suspecte in 2003. Samen met mijn broer Zouzou maakte ik de voorstelling Deleeuw van Vlaanderen en het jongerenstuk Vive!Aldi, waarin we de Aldi parodieerden met mensen van de tweede en derde generatie als goedkope producten.

\section{Waren er theaterfiguren in het Vlaamse theaterlandschap die je inspireerden?}

C.B.C.: Alain Platel had een grote invloed op mij. Bijvoorbeeld in de voorstelling Iets op Bach zag ik het vermengen van stijlen, het themavan de grootstad en de kracht van gelaagdheid in een stuk. Toch vond ik dat er nog iets ontbrak. Er was ontroering, esthetiek, maar het schuurde voor mij nog niet genoeg. Volgens mijn broer en mij moest een voorstelling hard schuren. We hadden een harde jeugd meegemaakt en wilden die realiteit onverbloemd op scene zetten. Ook wilden we verhinderen dat het publiek achterover ging leunen. Toen ik uiteindelijk na de opvoering van Vive!Aldi felicitaties per sms van Alain Platel ontving, was ik uiteraard in de zevende hemel.

Uiteindelijk konden we ons gezelschap Union Suspecte laten uitgroeien onder de vleugels van het Nieuwpoorttheater. Geert Opsomer was daarbij zeer invloedrijk. Het was tegelijk de periode dat ook Benjamin Verdonck en Abattoir Fermé er een werkplek kregen. Heel boeiende tijden waren dat. We gingen samenwerkingen aan, bijvoorbeeld met theatermakers als Arne Sierens voor de voorstelling Broeders van Liefde. We hadden immers vele zaken gemeenschappelijk: belang van humor, spelen

- L'Afrique c'est chic, Action Zoo Humain, 2010.
(2) Ook in De

Waarheidscommissie verkozen de drie Senegalese artiesten de illegaliteit boven een terugkeer naar Senegal na de voorstelling. Het vertrek was, echter zonder medeweten van de ploeg, goed voorbereid. Zo waren er stand-ins opgeleid om de laatste voorstelling af te werken. De hele scène was bovendien nog frappanter omdat er tijdens elke voorstelling werd gevraagd aan het publiek of het gerechtvaardigd was dat de broers Ben Chikha de paspoorten van de drie dansers bijhielden.

Het grootste deel van het publiek antwoordde telkens 'neen'. 


\section{Readings}

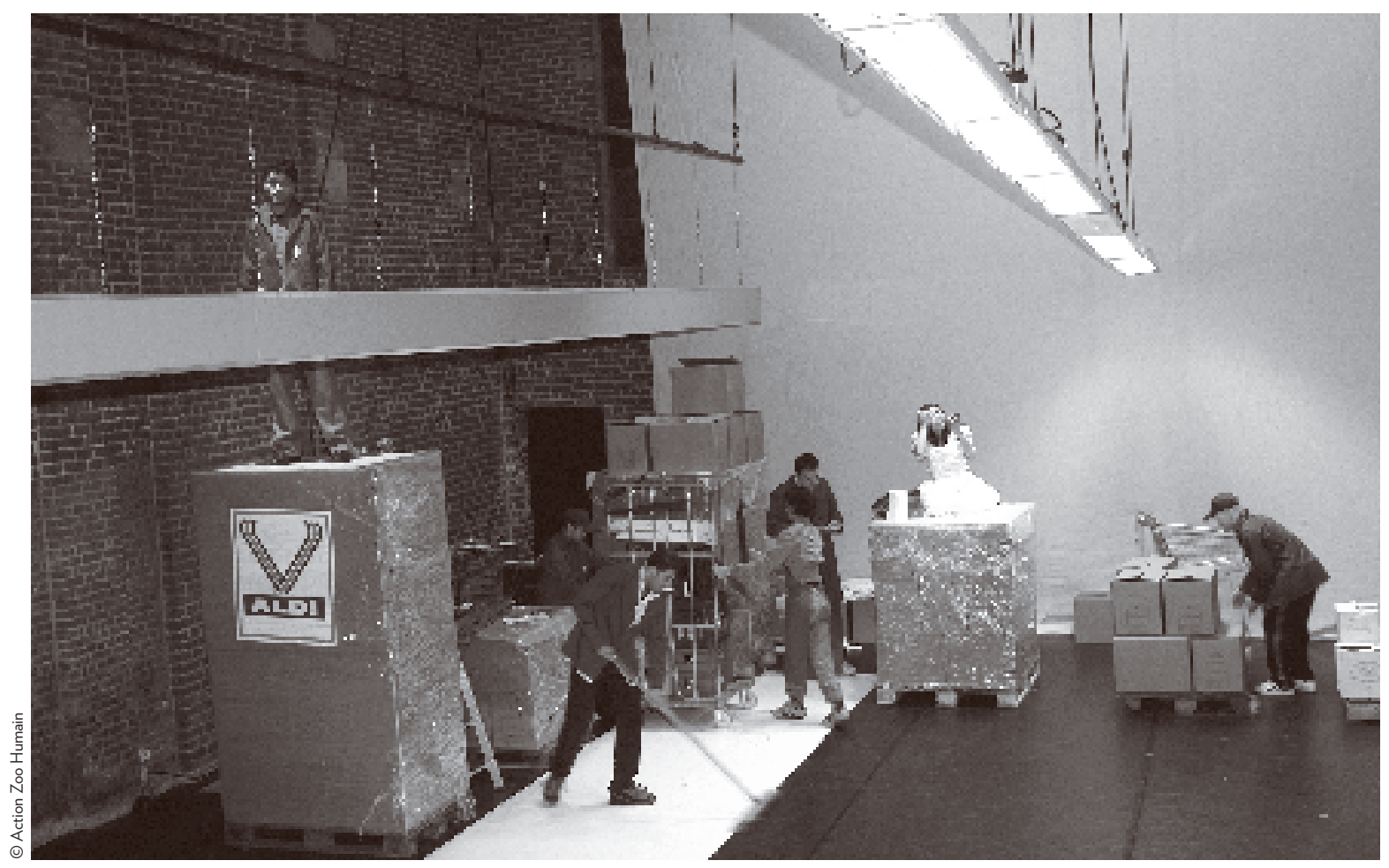

- Vive!Aldi,

Union Suspecte, 2004.

met stereotypen, het ontbreken van een repertoire, fascinatie voor het lukken en mislukken... Toch merkte ik dat we een aantal theatercodes anders interpreteerden. Hij speelde op de ontroering, zelfs verheerlijking van de kleine mens. De kleine Vlaming, armen, de vrouw, de underdog... Dat was voor mij uiteindelijk problematisch. Met de verheerlijking van de sukkelaar op het podium bewijs je volgens mij de sukkelaar geen dienst. Toch was die samenwerking heel erg leerrijk, want zo beseften we dat we elk onze eigen stijl hebben en dat er geen recept is voor goed theater. Ik merkte dat theater niet zo universeel is en dat iedereen werkt met eigen codes, met zijn of haar eigen realiteit. Met een migratieachtergrond bekijk je de zaken soms anders. Je bent gevoeliger voor bepaalde stereotypen, die uiteindelijk zeer natuurlijk zijn omdat alle mensen in hun hoofd op zoek gaat naar vormen van simplificatie. En die vormen hangen samen met de gemeenschap waartoe je behoort, en met je opvoeding.

Met de voorstelling We People (2007) koos Union Suspecte nochtans niet voor de kritische benadering van stereotypen, maar werd via de strategie van Publieksbeschimpfung het stereotiepe beeld van de woedende en machteloze allochtoon net versterkt.

C.B.C.: Dat klopt. Het was een voorstelling zonder kritiek op de eigen gemeenschap. De kritiek kwam op het publiek te liggen, zonder enige nuances. Voor die 
voorstelling werkte mijn broer samen met Ruud Gielens. Met de strategie van Publieksbeschimpfung meende Gielens dat de in yourface-boodschap die we wilden uitdragen beter zou overkomen. De voorstelling speelde bovendien in de periode van de vele migrantenrellen in Antwerpen en Anderlecht, en met de controverse rond Abou Jahjah. ${ }^{3}$ Je kon de voorstelling beschouwen als een overreactie op het werk van Platel dat niet genoeg schuurde. Uiteindelijk vond de pers de voorstelling geweldig en werd ze zelfs geselecteerd voor het theaterfestival.

Maar voor mij was het toen gedaan met Union Suspecte. Dit was mijn artistieke richting niet. We hebben er heel veel discussies over gehad. De voorstelling bevestigde volgens mij vooral de stereotypen, terwijl de essentie van Union Suspecte net het overstijgen van het wij-zijdiscours was. Het bevestigde het beeld dat in de kranten verscheen, en je voelde dat journalisten daarop kickten. Maar je stimuleert geen dialoog met zo'n voorstelling.

Met Action Zoo Humain zijn jullie in elk geval opnieuw de weg ingeslagen van de dialoog, zoals blijkt uit de voorstelling van De Waarheidscommissie. Wat brengt de toekomst?

C.B.C.: Ik weet het niet. Alles is nog open. Momenteel ontwikkelen we een Vlaams Paviljoen voor de volgende wereldtentoonstelling in Dubai 2020. We zijn op zoek naar de identiteit van de Vlaming. Daarvoor starten we in Dilbeek, 'waar de Vlamingen thuis zijn', en gaan op tournee. We prostitueren onszelf met een transformatie tot 'ondernemer-kunstenaar'. We verzamelen privé-fondsen om ons project te ondersteunen, want dat is toch wat het huidige kunstenbeleid wil: steeds meer privaat kapitaal halen uit systemen als crowdfunding in plaats van de reguliere subsidiekanalen. Dubai is de nieuwe way of life geworden, met zijn mystiek van kopen en verkopen, bouwen en verbouwen, van meer en meest. Men kijkt er neer op de Europeanen en dat zorgt voor een heel ander perspectief. Europeanen en Amerikanen die dansen naar de pijpen van islamitische Dubaiers, het is een raar gezicht. En dat terwijl slechts tien procent van de inwoners van Dubai autochtoon is. Dubai is de plaats bij uitstek waar de realiteit één groot theater wordt.

Uiteindelijk is voor mij álles theater. Theatraliteit is volgens mij een wezenlijk onderdeel van de realiteit, en van haar diverse waarheden. Maar pas op: ik ben geen postmodernist! Die Wahrheit ist konkret, zo stond te lezen boven het bureau van Bertolt Brecht. Om de waarheid kun je niet heen, ook al kent die waarheid veel nuances. I
(3) Dyab Abou Jahjah treedt tot op heden op als de fel gecontesteerde spreekbuis van de Arabische migranten in de Belgische media. In 2007 werd hij veroordeeld tot één jaar effectieve celstraf omwille van het aanzetten tot rellen. Die rellen braken op 26 november 2002 uit op de Turnhoutsebaan in Borgerhout nadat een islamleraar was neergeschoten door een buurman. Een groep allochtonen meenden dat racistische motieven aan de basis van de moord lagen. Uiteindelijk werd Abou Jahjah in 2008 in hoger beroep vrijgesproken.

(4) In de gemeente Dilbeek worden bezoekers op diverse plaatsen verwelkomd met borden waarop het opschrift 'Waar Vlamingen THUIS zijn' te lezen staat, en die verwijzen naar een campagne uit 1978 naar aanleiding van het Egmontpact. Met dit pact, dat de regering uiteindelijk deed vallen, werd de basis gelegd van de omvorming van België naar een federale staat met taalgemeenschappen. Vlamingen in de Brusselse rand meenden dat door de verfransing het Nederlandstalige karakter van hun gemeente onder druk kwam te staan. 